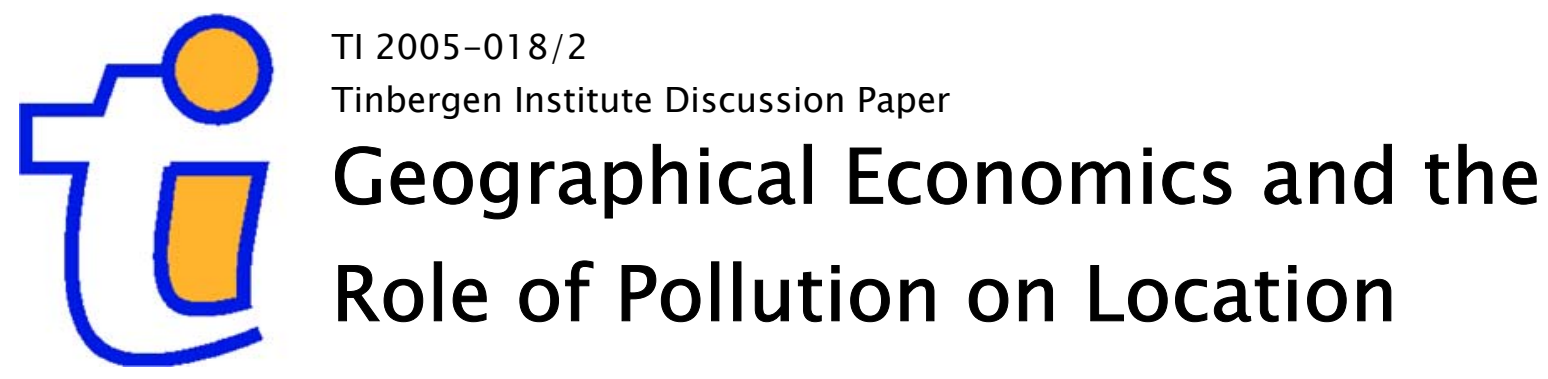

Charles van Marrewijk 
Tinbergen Institute

The Tinbergen Institute is the institute for economic research of the Erasmus Universiteit Rotterdam, Universiteit van Amsterdam, and Vrije Universiteit Amsterdam.

Tinbergen Institute Amsterdam

Roetersstraat 31

1018 WB Amsterdam

The Netherlands

Tel.: $\quad+31(0) 205513500$

Fax: $\quad+31(0) 205513555$

Tinbergen Institute Rotterdam

Burg. Oudlaan 50

3062 PA Amsterdam

The Netherlands

Tel.: $\quad+31(0) 104088900$

Fax: $\quad+31(0) 104089031$

Please send questions and/or remarks of nonscientific nature to driessen@tinbergen.nl.

Most TI discussion papers can be downloaded at http://www.tinbergen.nl. 


\title{
Geographical economics and the role of pollution on location
}

\author{
CHARLES VAN MARREWIJK \\ Department of Economics, H8-10 \\ Erasmus University Rotterdam \\ P.O. Box 1738, 3000 DR Rotterdam, the Netherlands \\ Email: vanmarrewijk@few.eur.nl \\ Tel. *31-10-4081393 Fax *31-10-4089146
}

This version: January 2005

\begin{abstract}
Geographical economics analyzes the endogenous determination of the location of economic activity in a general equilibrium framework. We investigate the impact of pollution by focusing on the interaction between location advantages and negative pollution externalities associated with local production. We distinguish between two goods (food and manufactures) and two factors of production (mobile human capital and immobile unskilled labor) and show that agglomeration of economic activity tends to become less attractive with pollution, and thus less likely. Moreover, we provide a simple necessary and sufficient condition for the spreading of economic activity to become more attractive, and thus more likely.
\end{abstract}

JEL codes: F0, Q0, R0

Key words : Geographical Economics, Pollution, Location

An earlier version of this paper was presented at the workshop Spatial Environmental Economics, May 9-10, 2003, Heidelberg, Germany. I am grateful to the Interdisciplinary Institute for Environmental Economics, more specifically to Klaus Conrad, Malte Faber, and Martin Quaas, for organizing the workshop and inviting me to participate. I would like to thank the workshop participants, in particular Switgard Feuerstein and Martin Quaas, for useful comments and suggestions. 


\section{Introduction}

Long ago, Bertil Ohlin (1933) asked for an integration between economic geography and international economics as, in some sense, both fields of economics are concerned with the distribution of economic activity across space and the concomittant interactions between centers of economic activity this entails. Paul Krugman's (1991) seminal contribution can be seen as a belated effort to provide such an integration, which set in motion a 'new' field of economics, based on insights developed in various other fields of economics, such as international economics, economic geography, regional science, urban economics, industrial organization, and economic growth. Initially, the new mix was termed 'New Economic Geography', but the more appropriate name 'Geographical Economics' is now becoming more popular, basically because as Brakman, Garretsen, and Van Marrewijk (2001), who provide and overview of the literature, argue: the approach is trying to put more geography into economics, rather than more economics into geography.

Without going into too much detail on the debate of the 'new'-ness of geographical economics, it is fair to conclude that it is the first approach which has the endogenous determination of the size of economic activity in different locations in a general equilibrium setting at the center of economic analysis. In essence, a discussion about locational competition is a discussion about the importance of geography in a very broad perspective. The Dutch Ministry of Economic Affairs (1999, pp. 114-5), for example, formulated three key characteristics of location policy: "a competitive location policy is a comprehensive policy...that includes all aspects that define the attractiveness of a location." Similarly, during the European Council meeting of the EU in Lisbon in March 2000, for example, the EU member states agreed upon a (benchmarking) method to determine the competitiveness of the EU economies. To this end no less than 54 indicators were devised. In this respect, it is remarkable that the geographical economics literature has largely neglected the role of the environment in determining the location decisions of firms and workers, with the exception of the work of Brakman et al. (1996) on the importance of congestion for explaining the economic viability of small economic centers and of Brakman et al (1999) for the link between congestion and Zipf's Law, the remarkable empirical regularity on the size distribution of cities. 
In contrast, the environmental economics literature has largely ignored the interaction between pollution and environmental degradation on the one hand and the location of economic activity on the other. For example, in answering questions concerning the optimal economic growth path in the presence of (non-renewable) resources, the literature has used two main types of models. Initially, the focus was on the neoclassical model, see Stiglitz (1974), Garg and Sweeney (1978), Dasgupta and Heal (1979) or Fisher and Van Marrewijk (1998). More recently, the focus has shifted to versions of endogenous growth models, see Van Marrewijk, Van der Ploeg and Verbeek (1993), Aghion and Howitt (1998), Scholz and Ziemes (1999), Barbier (1999) or Grimaud and Rouge (2003). An overview of the structural similarities and differences between these two approaches is provided in Van Marrewijk (1999), see also Withagen (1999). In both cases, long-term growth is possible under certain technological conditions. The pollution effects of the use of (non-renewable) resources, leading for example to increases in $\mathrm{CO}_{2}$ (greenhouse gas) or $\mathrm{SO}_{\mathrm{x}}$ and $\mathrm{NO}_{\mathrm{x}}$ (acid rain), are analyzed in Kolstad and Krautkraemer (1993), Tahvonen (1997, 2001), and Schou (2000).

The objective of this paper is, therefore, to partially fill the void in the literature by analyzing the interaction between location of economic activity and pollution. There are, undoubtedly, both stock and flow aspects to be considered in this regard in a truly dynamic setting. Moreover, pollution may simultaneously affect the production process and a household's utility. However, progress in science is taken step by step, usually by focusing on particular (new) aspects, while temporarily ignoring other aspects. Kolstad and Krautkraemer (1993), for example, provide the following warning: "in general, it is difficult or impossible to characterize the qualititative features of a model with three state variables." For this reason, Schou (2000) focuses the analysis on the flow effects of pollution for the production process, leading to an increased depreciation of capital. Similarly, this paper focuses on the flow effects of pollution for a household's utility, see also Smulders and Gradus (1993) or Aghion and Howitt (1998). We will take the technological conditions which allow for sustainable economic growth for granted and instead focus the dynamic analysis on the determination of the location of economic activity in the presence of pollution affecting a household's utility. In Schmutzler's (2003) terminology, this is a type-3 analysis (non-endogenous policy with endogenous location and environment). 


\section{The model}

To analyze the interaction between pollution externalities caused by production, which is detrimental to consumer welfare, and the location of industries, we extend the location model developed by Forslid (1999), Ottaviano (2001), and Forslid and Ottaviano (2003). This model, which distinguishes between a mobile and an immobile factor of production, is rapidly becoming the benchmark model for analyzing location decisions as its elegant structure allows for explicit analytic solutions, see for example Andersson and Forslid (2003) and Baldwin and Krugman (2004) on tax competition and economic integration and Brakman, Garretsen and Van Marrewijk (2002) for a more detailed analysis of public goods. The objective of the paper is similar in spirit to that of Rauscher (2003) and Quaas (2003), who analyze the interaction between location and environment using Krugman's (1991) initial core model of geographical economics as point of departure. Despite simplifying (partial equilibrium) assumptions, analytic complications in the models of Rauscher and Quaas prevent the derivation of clear analytic results, such that their conclusions are based mostly on the outcome of computer simulations. As mentioned above, the main advantage of the Forslid-Ottaviano model, which has virtually identical core-periphery versus spreading location implications as Krugman's model, is that it can be analytically solved, which also allows for clear results if we take pollution effects into consideration, see propositions 1-3 below.

We distinguish between two countries, for lack of imagination called 1 and 2. In the sequel the subindex $j=1,2$ is used to identify the country. The two countries have access to the same level of technology and each country can produce two types of goods, namely food $(F)$ and manufactures $(M)$ using two factors of production, namely unskilled labor $(L)$ and human capital $(H)$. In accordance with stylized empirical facts, we assume that only human capital is mobile between the two countries, see the literature cited immediately above. Associated with the domestic production levels of food and manufactures is a local negative externality, called pollution $(P)$. Obviously, production of either food or manufactures could also give rise to global pollution externalities, negatively affecting consumer welfare in both countries. Since such global pollution does not interact with the location decisions of firms and human capital, which is the topic of this paper, it is ignored in the sequel. 
The utility function $(U)$ for country $j$ is given by

$$
U_{j}=M_{j}^{\delta} F_{j}^{(1-\delta)}\left(1+P_{j}\right)^{-\theta} ; \quad 0<\delta<1 ; \quad 0 \leq \theta,
$$

where $\delta$ represents the share of income spent on manufactures and $\theta$ measures the extent of the pollution externality. Food is produced under constant returns to scale using only unskilled labor as an input. If we let food be the numéraire (the price of food is one), and assume free trade of food, no transport costs for food or other trade impediments, a suitable choice of units (one unit of labor is required to produce one unit of food) ensures that the remuneration paid to unskilled labor is also equal to one.

There are many varieties of manufactures, identified by the index $i$, with a constant elasticity of substitution $\sigma$ between varieties. Country $j$ produces $n_{j}$ of the varieties.

$$
M_{j}=\left(\sum_{i=1}^{n_{1}+n_{2}} c_{j i}^{\gamma}\right)^{1 / \gamma} ; \quad \sigma \equiv \frac{1}{1-\gamma}>1,
$$

It is well known that maximization of consumer utility based on equations (1) and (2) ensures that the price elasticity of demand for a particular variety is equal to the parameter $\sigma$, provided the number of varieties is large enough.

Each variety is produced under increasing returns to scale using both human capital and unskilled labor. The fixed cost component requires one unit of human capital and the variable cost component requires $\gamma$ units of unskilled labor per produced unit of manufactures (a normalization used to minimize notation in the sequel). If we let $w_{j}$ be the wage rate for human capital in country $j$, the cost of producing $x_{j i}$ units of manufacturing variety $i$ in country $j$ equals

$$
w_{j}+\gamma x_{j i}
$$

Since all manufacturing firms in a country face the same cost and demand conditions they will all make the same pricing and production decisions, such that we can drop the subindex $i$ for the firm in the sequel. Let $p_{j}$ be the price of a locally produced manufacturing variety in country $j$. Under Dixit-Stiglitz (1977) monopolistic competition each variety is produced by a single firm with a standard mark-up price

$$
\gamma p_{j}=\gamma \Leftrightarrow p_{j}=1
$$


To introduce spatial aspects into the model in a non-trivial sense without the need to model a separate transport sector Samuelson (1952) introduced the concept of iceberg trade costs, assuming that if $T \geq 1$ units of a manufacturing variety are shipped from one country to the other, only one unit arrives at its destination. This increase in the marginal production costs together with the fact that the price elasticity of demand for any variety is the same in the two countries, implies that the price charged in the other country is $T$ times as high as the price charged at home.

Firms will enter or exit the manufacturing sector in each country until (excess) profits are zero. Using equations (2)-(4) this implies that the equilibrium output per firm $x_{j}$ in country $j$ equals

$$
p_{j} x_{j}=w_{j}+\gamma x_{j} \Leftrightarrow x_{j}=\sigma w_{j}
$$

The size of a representative manufacturing firm in a country is therefore directly proportional to the wage rate paid to human capital in that country, as a higher wage rate implies higher fixed costs which necessitates a larger scale of production to recuperate those costs.

The level $H_{j}$ of human capital in country $j$ is only used in the fixed cost component for the production of manufactures, which therefore directly determines the number of manufacturing varieties $n_{j}$ produced in country $j$ as a function of human capital

$$
n_{j}=H_{j}
$$

The level $L_{j}$ of unskilled labor in country $j$, on the other hand, is used both for the production of food and for (the marginal cost component of) the production of manufactures. Since we know the equilibrium size of production for a representative firm in country $j$, see equation (5), it follows that $\gamma n_{j} x_{j}$ unskilled workers are necessary for the production of manufactures, such that the level of food production $F_{j}$ is given by

$$
F_{j}=L_{j}-\gamma n_{j} x_{j}
$$


The domestic production of both food $F_{j}$ and manufactures $n_{j} x_{j}$ gives rise to local pollution $P_{j}$, which negatively affects domestic utility. We assume there is no inherent difference between the two countries regarding environmental regeneration, such that the same function $P($.$) holds for both countries, and that an increase in$ output from either food production or manufactures production increases pollution.

$$
P_{j}=P\left(n_{j} x_{j}, F_{j}\right) ; \quad P_{n x}{ }^{\prime} \geq 0, P_{F}^{\prime} \geq 0
$$

The analytic results derived in the sequel hold for the quite general specification given in equation (8), which may exhibit constant, increasing or decreasing returns to scale and which allows for arbitrary elasticities of substitution between the two 'inputs' food and manufactures in 'producing' the output pollution. For illustrative purposes, however, we use a more specific pollution function in our simulations, in which the parameter $\beta$ measures the relative importance of manufactures production for environmental degradation, see equation (8').

$$
P_{j}=\left(n_{j} x_{j}\right)^{\beta}\left(F_{j}\right)^{1-\beta} ; 0 \leq \beta \leq 1
$$

As there are two factors of production in a country, namely unskilled labor $L_{j}$ (with a reward equal to one) and human capital $H_{j}$ (with a wage rate equal to $w_{j}$ ), and the two production sectors food and manufactures do not make any profits in equilibrium, either as a result of constant returns to scale and perfect competition (food) or as a result of entry or exit until profits are zero (manufactures), the income level $Y_{j}$ in country $j$ is given by

$$
Y_{j}=w_{j} H_{j}+L_{j}
$$

It is convenient to define the 'free-ness of trade' parameter $\phi$ as a function of trade costs and the elasticity of substitution as follows: $\phi \equiv T^{1-\sigma}$. The free-ness of trade parameter ranges between 0 and $1 ; \phi=0$ represents autarky and $\phi=1$ represents free trade (no obstacles to the movement of manufacturing varieties of any kind whatsoever). Using this definition, the market clearing condition for the production of a variety of manufactures in country $j$ equals 


$$
\begin{aligned}
& p_{j} x_{j}=\frac{p_{j}^{1-\sigma} \delta Y_{j}}{I_{j}^{1-\sigma}}+\frac{\phi p_{k}^{1-\sigma} \delta Y_{k}}{I_{k}^{1-\sigma}} ; \phi \equiv T^{1-\sigma} \\
& I_{j}=\left(p_{j}^{1-\sigma} n_{j}+\phi p_{k}^{1-\sigma} n_{k}\right)^{1 /(1-\sigma)},
\end{aligned}
$$

where $I_{j}$ is country $j$ 's exact price index of manufactures.

The structure of the model ensures that the locally charged price for a manufacturing variety is equal to unity, see equation (4). Obviously, this greatly simplifies the expressions for the price index in (11) and equilibrium for the production of a variety of manufactures in (10). Substituting this and equations (5) and (9) in equation (10) gives us two linear equations in the endogenous wage rate for human capital which can easily be solved analytically.

In the sequel we normalize the total stock of human capital to unity $\left(H_{1}+H_{2}=1\right)$ and analyze two countries with an identical stock of unskilled labor $\left(L_{1}=L_{2}=L\right)$. Moreover, to ensure that the food sector is active in both countries we assume that a single location alone cannot supply world demand. As Forslid and Ottaviano (2003) show, this imposes the restriction $\delta<\sigma /(2 \sigma-1)$ on the structural parameters, that is food consumption must be sufficiently important $(\delta$ small) and consumers have a sufficient liking for variety ( $\sigma$ small).

\section{Equilibrium}

To analyze the location decisions of firms and their mobile inputs, in this case human capital, the geographical economics literature distinguishes between short-run equilibria and long-run equilibria and focuses on stability properties. The short-run equilibrium is derived for a given distribution of the mobile factor human capital, along the lines set out above. The stability analysis focuses on the distribution properties of the real wages of human capital, $\omega$ say, which under standard circumstances is an accurate reflection of indirect utility in view of the exact price indices. Usually, an ad hoc adjustment equation is specified in which human capital moves from countries with low real wages to countries with high real wages, although we should point out that this can be grounded in evolutionary game theory, see Weibull (1995), or otherwise justified, see chapters 6 and 10 of Brakman, Garretsen, 
and Van Marrewijk (2001) and the references cited there. In this framework, however, investigating only the distribution properties of the real wages of human capital is not enough as this ignores the externalities associated with pollution and the negative impact this has on welfare. Instead, to determine the relocation decisions of human capital, we should focus on the indirect utility function, $v_{j}$ say, associated with equation (1) in relative terms

$$
\frac{v_{1}}{v_{2}}=\frac{w_{1}}{w_{2}} \frac{I_{2}^{\delta}}{I_{1}^{\delta}} \frac{\left(1+P_{2}\right)^{\theta}}{\left(1+P_{1}\right)^{\theta}} \equiv\left(\frac{\omega_{1}}{\omega_{2}}\right)\left(\frac{1+P_{2}}{1+P_{1}}\right)^{\theta}
$$

The first term on the right-hand-side of equation (12) epresents the traditionally emphasized relative real wage and the second term represents the relative pollution externality which also affects welfare, and therefore location decisions. We will assume that human capital moves from country 1 to country 2 if the ratio in equation (12) is larger than one, and vice versa if it is smaller than one.

Figure 1 Wages, prices, and income levels; example 1 and $T=1.35$

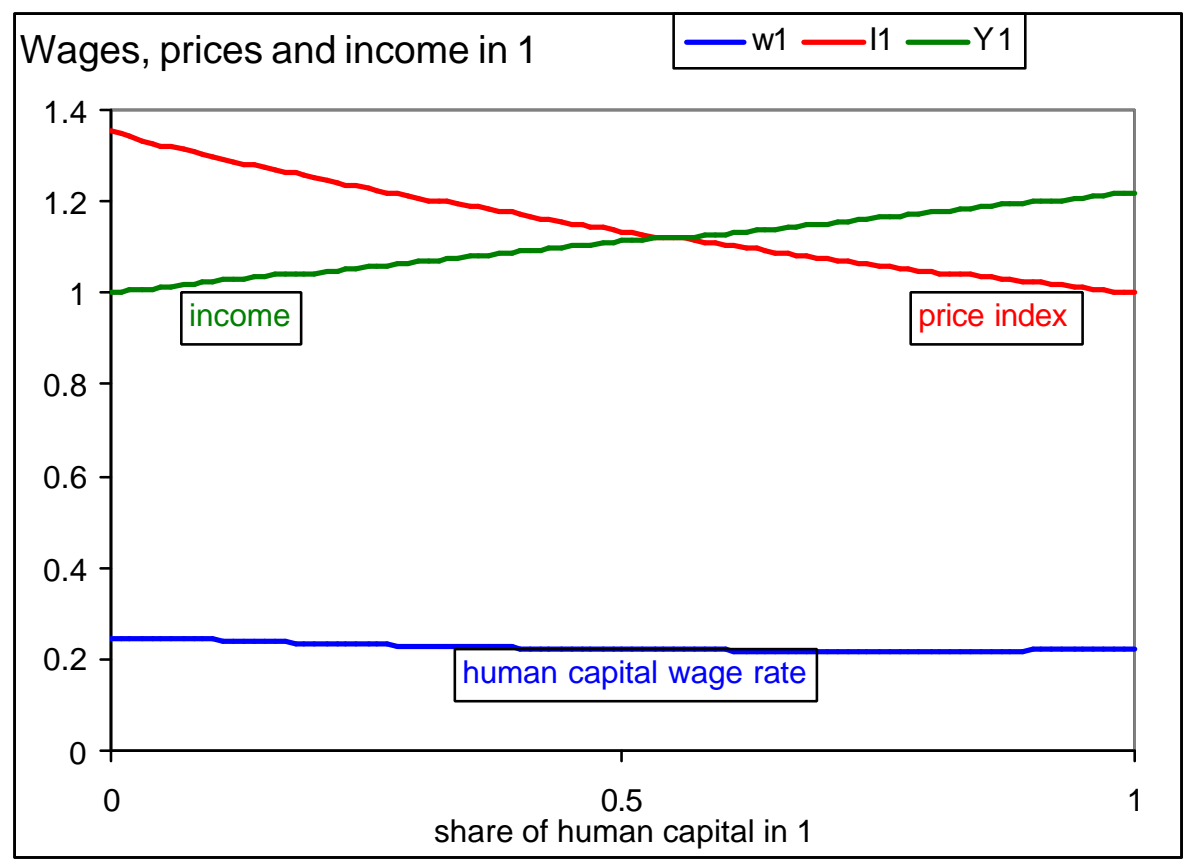

\section{Some examples}

The workings of the model are best illustrated using some specific examples, see Table 1 for some fairly arbitrarily chosen parameter setting suitable for discussing the main implications. In view of the symmetric nature of the model for all short-run 
exogenous variables, except for the distribution of human capital, we can focus attention on country 1 as the results for country 2 can be read off the same diagram from the reverse perspective (i.e. at ' 1 - share of human capital in 1' in the figures).

Table 1 Parameters for example 1

\begin{tabular}{l|cc}
\hline Economic interpretation & parameter & value \\
\hline Share of income spent on manufactures & $\delta$ & 0.3 \\
Elasticity of substitution between varieties & $\sigma$ & 3 \\
Disutility of pollution & $\theta$ & 0.1 \\
Relative impact of manufactures for pollution & $\beta$ & 0.6 \\
Unskilled labor supply & $L$ & 1
\end{tabular}

Naturally, as the share of human capital located in country 1 rises the income level also rises, as illustrated in Figure 1. The more abundant availability of human capital has limited, non-monotonic effects on its factor reward. More specifically, the wage rate $w_{1}$ usually declines very slowly as human capital accumulates, but starts to rise again in the neighbourhood of complete agglomeration of all human capital in country 1. Finally, Figure 1 also shows that as human capital accumulates in country 1 and more locally produced varieties of manufactures become available, the exact price index of manufactures declines as the consumers in country 1 no longer have to pay for the trade costs.

Figure 2 focuses on the production of food and manufactures and their effect on the pollution level as human capital accumulates. Obviously, as the share of human capital located in country 1 rises the production of manufactures $n_{1} x_{1}$ also rises, almost exclusively because the number of varieties $n_{1}$ produced in country 1 increases as the changes in the wage rate are too small (see the discussion above) to have a significant impact on the scale of production $x_{1}$, see equation (5). As also illustrated in Figure 2, the increase of human capital in country 1 and its concomittant expansion of the manufacturing sector draws away unskilled labor from the production of food, which therefore declines, towards the production of manufactures. We have ensured, however, that the production of food does not completely disappear even if all human capital is agglomerated in country 1, see the discussion at the end of section 2 . 
Figure 2 Pollution and production of food and manufactures; example 1 and $T=1.35$

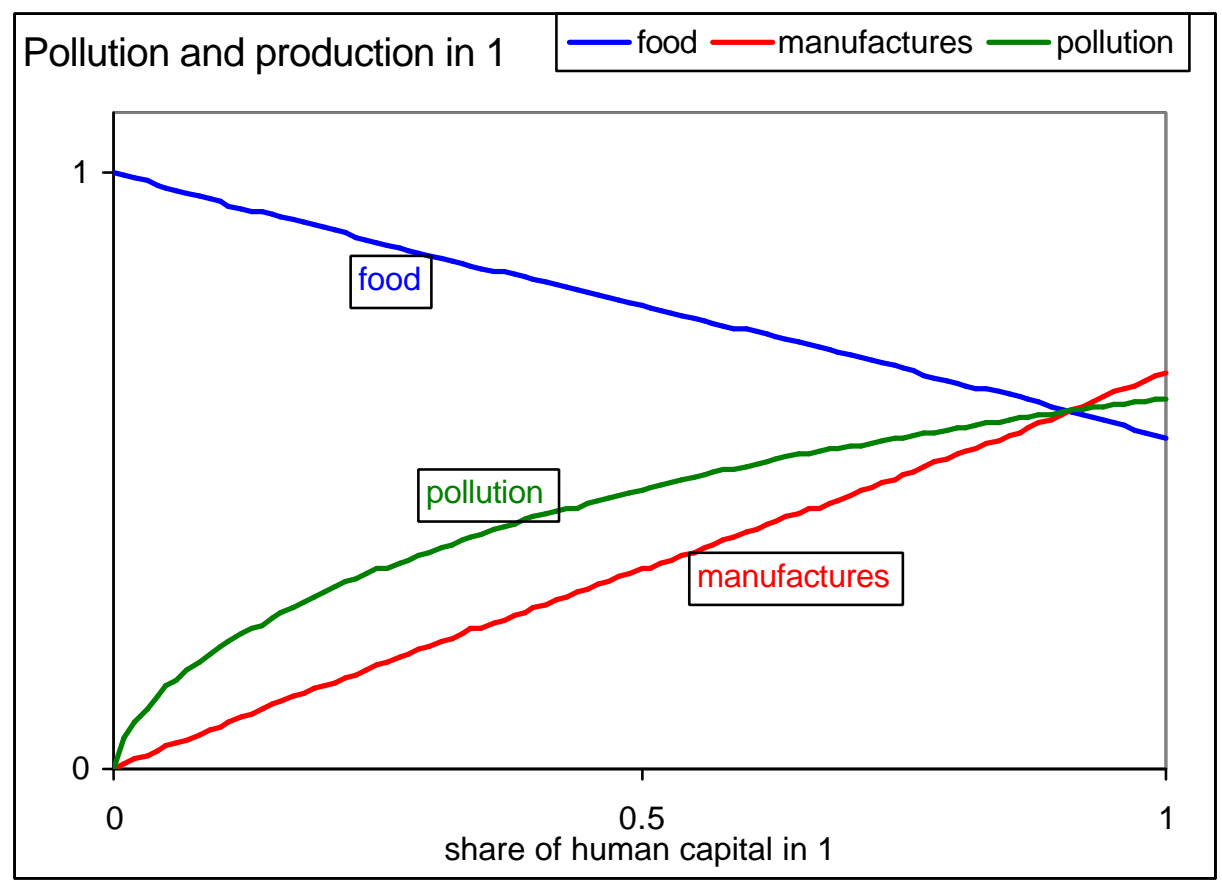

Figure 2 illustrates how, as economic activity (human capital, income, and the production of manufactures) rises in country 1, the associated pollution level also increases. We analyze this aspect in more detail below, but would like to note at this point that, by construction, the pollution level is zero if there is no manufacturing activity at all in country 1 , see equation (8). This is not an artefact of the model, but a normalization of the level of pollution in the absence of manufacturing activity.

Figure 3 illustrates the welfare level $v_{1} / v_{2}$ of human capital in country 1 relative to country 2 (labeled 'with pollution' in the figure) and the real wage $\omega_{1} / \omega_{2}$ of human capital in country 1 relative to country 2 (labeled 'ignore pollution' in the figure). Obviously, if the available human capital is equally divided between the two countries, henceforth referred to as 'spreading' of economic activity, the welfare levels and the real wage rates are the same in the two countries. Human capital has, at the spreading equilibrium, no incentive to relocate, such that an equal division of human capital is always a long-run equilibrium. As illustrated by the ignore pollution' line in Figure 3, if the share of human capital in country 1 is lower than in country 2 , the real wage is higher in country 1 than in country 2 , such that human capital will relocate from country 1 to country 2 . Under these circumstances, therefore, spreading of economic activity is a stable equilibrium if we look 
exclusively at the real wage effects and ignore the pollution effects. Finally, Figure 3 illustrates that including the pollution effects strenghtens the stability properties of the spreading equilibrium as the 'with pollution' line in Figure 3 is steeper than the ‘ignore pollution’ line.

Figure 3 Relative welfare of human capital; example 1 and $T=1.35$

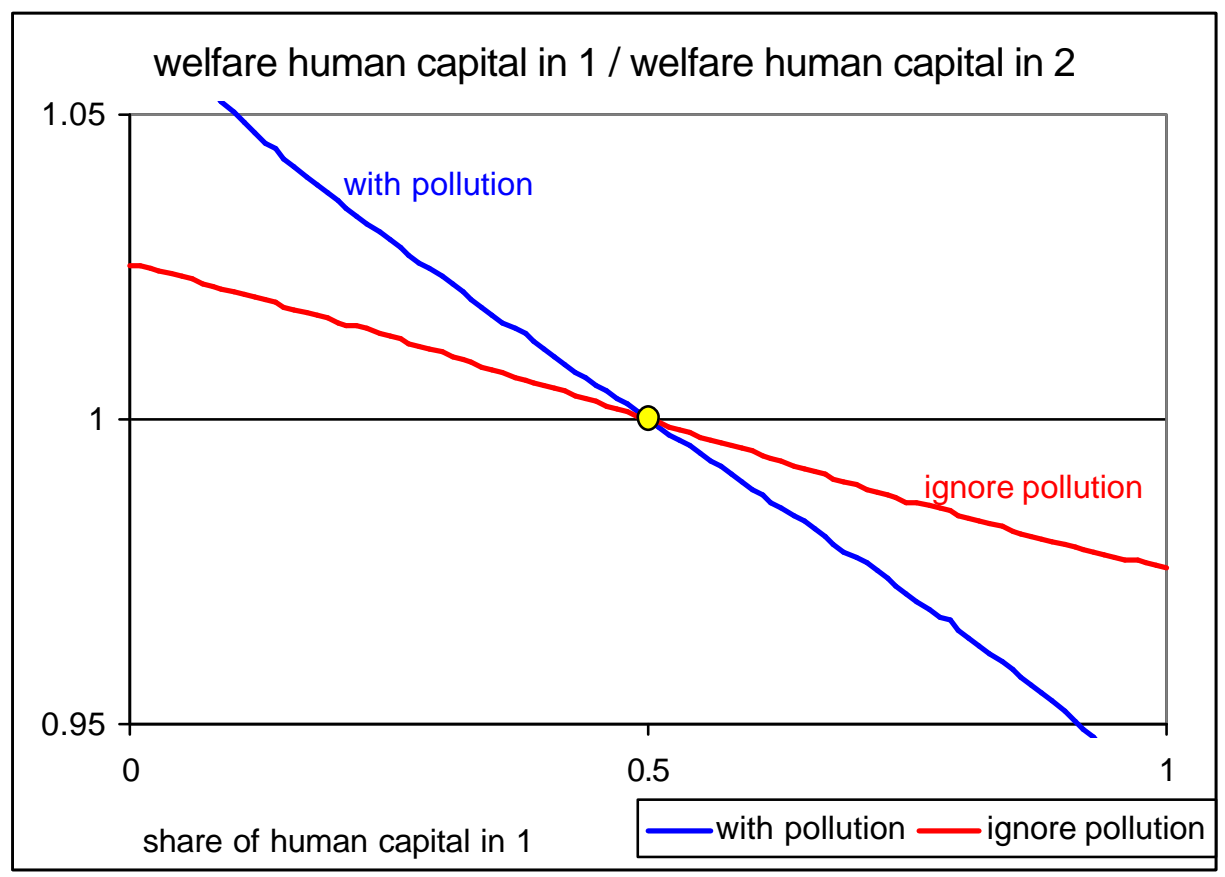

Figure 4 shows the welfare and real wage of country 1 relative to country 2 for two other choices of the trade costs $T$. The left-hand panel $(T=1.15)$ illustrates that for low trade costs spreading of economic activity is an unstable equilibrium if we ignore the pollution effects and agglomeration in one of the two countries is a stable equilibrium. For example, if initially more than half of the available human capital is located in country 1 we observe that the real wage is higher in country 1 than in country 2 , such that focusing only on real wages all human capital will agglomerate in country 1 . The reverse holds if initially less than half of all human capital is located in country 1 . However, if we include the pollution effects of the relocation of human capital in the left-hand panel of Figure 4, we observe that spreading of economic activity is a stable equilibrium whereas agglomeration is unstable. The inclusion of pollution effects therefore completely reverses the stability properties of the distribution of human capital. Something similar, although less dramatic, holds in the right-hand panel of Figure 4. If we ignore pollution effects, we see there are five longrun equilibria, alternately stable and unstable. More specifically, both agglomeration 
of economic activity (in either country 1 or country 2) and spreading of economic activity are stable equilibria. In between are two unstable partial agglomeration equilibria. Including the pollution effects, however, implies that spreading of economic activity is the only stable long-run equilibrium in the right-hand panel.

Figure 4 Welfare and real wage in country 1 relative to country 2
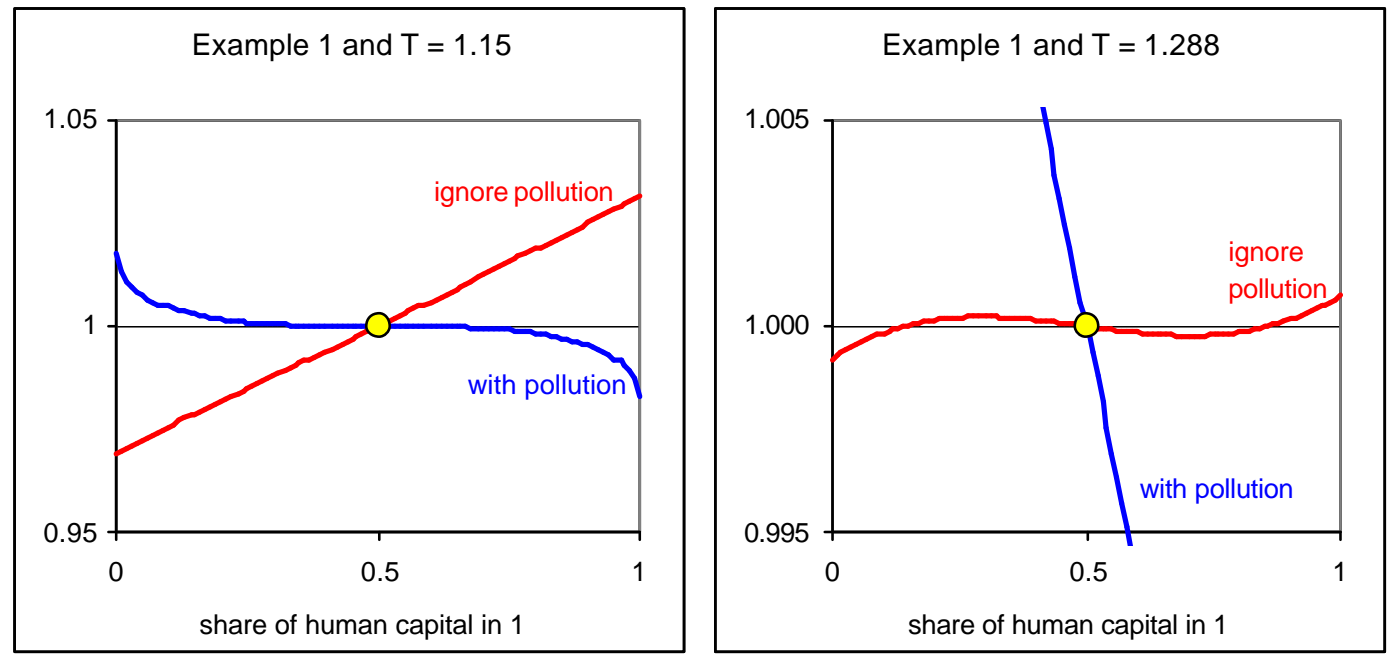

In all examples discussed above the inclusion of pollution effects makes the spreading of economic activity a more stable long-run equilibrium and simultaneously makes agglomeration of economic activity an unstable equilibrium if it was initially stable. Intuitively, this seems to make perfect sense: if a relocation of inputs raises income and economic activity, resulting in a rising level of pollution which negatively affects welfare, one would expect that agglomeration of economic activity becomes less attractive, and thus less likely, and spreading of economic activity becomes more attractive, and thus more likely. As we will see in the next section, this intuitive reasoning both is and is not justified.

\section{Stability analysis}

The geographical economics literature is interested in the stability properties of the long-run equilibria as this crucially influences the location decisions of firms and mobile factors of production. As we have seen from the examples above, depending on the structural parameters of the model either (i) spreading of economic activity may be the only stable equilibrium, or (ii) agglomeration of economic activity may be the only stable equilibrium, or (iii) both spreading and agglomeration of economic activity may be stable equilibria. It is therefore important to determine under which 
circumstances the various possibilities mentioned above occur. In this analysis it is customary to identify the sustainpoint and the breakpoint:

- The sustainpoint is that configuration of structural parameters for which agglomeration of economic activity ceases to be a stable equilibrium.

- The breakpoint is that configuration of structural parameters for which spreading of economic activity ceases to be a stable equilibrium.

\section{Stability analysis ignoring pollution effects ( $n p)$}

If pollution effects are ignored the stability properties of the model are exclusively dictated by the relative real wage rate. For notational convenience, let $h$ denote the share of human capital located in country 1. It can be shown, see Brakman, Garretsen, and Van Marrewijk (2002), that the relative real wage is equal to

$$
\frac{\omega_{1}}{\omega_{2}}=\frac{\sigma\left[2 \phi h+(1-h)\left(1+\phi^{2}\right)\right]+\left(\phi^{2}-1\right)(1-h) \delta}{\sigma\left[2 \phi(1-h)+h\left(1+\phi^{2}\right)\right]+\left(\phi^{2}-1\right) h \delta}\left(\frac{\phi h+1-h}{h+\phi(1-h)}\right)^{\delta /(1-\sigma)}
$$

The core-periphery structure of an agglomeration equilibrium is unstable, that is it cannot be sustained, for trade costs above the sustainpoint, that is for trade costs for which equation (13) evaluated at $h=0$ (or $h=1$ ) is equal to one. ${ }^{1}$ The spreading of economic activity is an unstable equilibrium, that is it breaks down, for trade costs below the breakpoint, which can be derived by differentiating equation (13) with respect to $h$ and evaluating at $h=0.5 .^{2}$ Forslid and Ottaviano (2003) show:

- $\phi_{b r e a k, n p}=\frac{(\sigma-\delta)(\sigma-1-\delta)}{(\sigma+\delta)(\sigma+\delta-1)}$

- $2 \sigma \phi_{\text {sustain, } n p}^{1-\delta /(-1)}-(\sigma+\delta) \phi_{\text {sustain, } n p}^{2}-\sigma+\delta=0$

- $\phi_{\text {sustain, } n p}<\phi_{\text {break,np }}$

where $n p$ is used as a mnemonic for 'no pollution'. In general, therefore, starting from very high initial trade costs, the free-ness of trade parameter $\phi$ is both below the sustainpoint and the breakpoint, such that spreading of economic activity is the only stable equilibrium. If trade costs are sufficiently reduced from their initial position, the free-ness of trade parameter $\phi$ rises above the sustainpoint, such that both spreading of economic activity and agglomeration are stable equilibria. Eventually, as

\footnotetext{
${ }^{1}$ More precisely, we have to take the limit as the share of human capital in country 1 approaches 0 or 1 .

${ }^{2}$ The breakpoint arises at the point where the derivative is equal to zero.
} 
trade costs fall even further the free-ness of trade parameter $\phi$ also rises above the breakpoint and agglomeration of economic activity is the only stable equilibrium.

\section{Core-periphery and spreading equilibrium with pollution}

Before we continue with the stability analysis of the model it is useful to derive and summarize some of the properties of the core-periphery (economic agglomeration) and economic spreading equilibria.

Proposition 1. The economic variables in the spreading equilibrium and the coreperiphery equilibrium with pollution are summarized in Table 2.

Table 2 Economic variables in the core-periphery and spreading equilibria

\begin{tabular}{|c|c|c|}
\hline & Spreading equilibrium & Core-periphery equilibrium \\
\hline wage rate & $w_{\text {spread }}=2 \delta L /(\sigma-\delta)$ & $w_{\text {core }}=2 \delta L /(\sigma-\delta)$ \\
\hline income & $Y_{\text {spread }}=\sigma L /(\sigma-\delta)$ & $\begin{array}{l}Y_{\text {core }}=(\sigma+\delta) L /(\sigma-\delta) \\
Y_{\text {periphery }}=L\end{array}$ \\
\hline manufactures & $n x_{\text {spread }}=\sigma \delta L /(\sigma-\delta)$ & $\begin{array}{l}n x_{\text {core }}=2 \delta \sigma L /(\sigma-\delta) \\
n x_{\text {periphery }}=0\end{array}$ \\
\hline food & $F_{\text {spread }}=\sigma(1-\delta) L /(\sigma-\delta)$ & $\begin{array}{l}F_{\text {core }}=[\sigma(1-2 \delta)+\delta] L /(\sigma-\delta) \\
F_{\text {periphery }}=L\end{array}$ \\
\hline pollution (8) & $P_{\text {spread }}=P\left(n x_{\text {spread }}, F_{\text {spread }}\right)$ & $\begin{array}{l}P_{\text {core }}=P\left(n x_{\text {core }}, F_{\text {core }}\right) \\
P_{\text {periphery }}=P(0, L)\end{array}$ \\
\hline pollution $(8)$, & $P_{\text {spread }}=\frac{(1-\delta)^{1-\beta} \delta^{\beta} \sigma L}{\sigma-\delta}$ & $\begin{array}{l}P_{\text {core }}=\frac{(\sigma(1-2 \delta)+\delta)^{1-\beta}(2 \delta \sigma)^{\beta} L}{\sigma-\delta} \\
P_{\text {periphery }}=0\end{array}$ \\
\hline
\end{tabular}

See the Appendix for a derivation of Table 2. Note that this framework emphasizes the distributional aspects of the core-periphery equilibrium relative to the spreading equilibrium as the wage rate is the same $\left(w_{\text {core }}=w_{\text {spread }}\right)$, the total income level is the same $\left(Y_{\text {core }}+Y_{\text {periphery }}=2 Y_{\text {spread }}\right), \quad$ as is the total production of food $\left(F_{\text {core }}+F_{\text {periphery }}=2 F_{\text {spread }}\right)$ and manufactures $\left(n x_{\text {core }}+n x_{\text {periphery }}=2 n x_{\text {spread }}\right) . \quad$ The example in section 3 , however, has already alerted the reader to the fact that this is a special phenomenon of the core-periphery versus the spreading equilibrium, as it does not hold for arbitrary distributions of human capital. In particular, the wage rate paid 
to human capital may vary, and hence the total levels of income, food production, and manufactures production.

\section{Sustainpoint with pollution}

Analyzing the impact of pollution effets on the stability of the agglomeration (coreperiphery) equilibrium is relatively straigthforward. First, we must acknowledge that the relocation decisions are dictated by the relative indirect utility levels given in equation (12), rather than the relative real wage rates given in equation (13). Second, we can evaluate this expression at one of the agglomeration equilibria, let's say at $h=0$, and at the sustainpoint $\phi_{\text {sustainnp }}$ if we ignore pollution effects. The above analysis then implies that the relative real wage $\omega_{1} / \omega_{2}$ is equal to one, such that the relative indirect utility level $v_{1} / v_{2}$ is equal to $\left[\left(1+P_{2}\right) /\left(1+P_{1}\right)\right]^{\ominus}$.

Since $P_{1}=P_{\text {periphery }}=P(0, L)$ if $h=0$ (the pollution level in the periphery if there is no manufacturing production), while $P_{2}=P_{\text {core }}$, it follows that $v_{1}>v_{2}$ if, and only if, $P_{\text {core }}=P\left(n x_{\text {core }}, F_{\text {core }}\right)>P(0, L)=P_{\text {periphery }}$. For pollution function ( $\left.8^{\prime}\right)$ this is equivalent to assuming that country 2 produces at least some food, that is it does not completely specialize in the production of manufactures. From the discussion at the end of section 2 we know that the latter requires the restriction $\delta<\sigma /(2 \sigma-1)$ on the parameters of the model. In general, if $P_{\text {core }}=P\left(n x_{\text {core }}, F_{\text {core }}\right)>P(0, L)=P_{\text {periphery }}$ the indirect utility level would be larger in country 1 than in country 2 at $\phi_{\text {sustainn }}$ for agglomeration in country 2 if we include pollution effects, such that the agglomeration equilibrium is unstable. Since the sustainpoint with pollution solves $v_{1} / v_{2}=1$, and assuming that economic agglomeration implies larger pollution levels in the core than in the periphery, for economic agglomeration in country 2 to be sustainable the negative pollution effect will have to be compensated by a strictly larger real wage in country 2 than in country 1: $\omega_{1} / \omega_{2}=\left([1+P(0, L)] /\left[1+P_{\text {core }}\right]\right)^{\theta}<1$. The set of standard economic parameters for which economic agglomeration is sustainable is therefore strictly smaller if we acknowledge pollution externalities, thus confirming the economic intuition suggested in section 3 . 
Proposition 2. The set of parameters $(\delta, \sigma, T)$, and thus $\phi \equiv T^{1-\sigma}$, for which the coreperiphery (economic agglomeration) equilibrium is sustainable is strictly smaller if we acknowledge pollution externalities as long as the pollution level in the core is higher than in the periphery, that is if $P_{\text {core }}=P\left(n x_{\text {core }}, F_{\text {core }}\right)>P(0, L)=P_{\text {periphery }}$. For pollution function (8') this is equivalent to the assumption that the core produces both goods, which holds if, and only if, $\delta<\sigma /(2 \sigma-1)$.

Proposition 2 implies in particular that, other things equal, the trade costs will have to be reduced further if there are pollution externalities to make the core-periphery equilibrium sustainable, thus making such an outcome less likely to occur. ${ }^{3}$

\section{Breakpoint with pollution}

The above analysis has shown that including pollution effects in the geographical economics model diminishes the stability of the core-periphery equilibrium. A similar conclusion regarding the acknowledgement of pollution effects on the stability properties of the spreading equilibrium can also be derived. Recall that $h$ denotes the share of human capital located in country 1 . We can then write all short-run endogenous variables in equation (12) as functions of $h$ and, for convenience, define $g(h) \equiv \mathrm{v}_{1}(h) / \mathrm{v}_{2}(h) \quad$ and the auxiliary functions $g_{1}(h) \equiv \omega_{1}(h) / \omega_{2}(h)$ and $g_{2}(h) \equiv\left[\left(1+P_{2}(h)\right) /\left(1+P_{1}(h)\right)\right]^{\ominus}:$

$$
g(h) \equiv \frac{v_{1}(h)}{v_{2}(h)}=\left(\frac{\omega_{1}(h)}{\omega_{2}(h)}\right)\left(\frac{1+P_{2}(h)}{1+P_{1}(h)}\right)^{\theta} \equiv g_{1}(h) g_{2}(h)
$$

It is important to note some of the properties of the functions just defined.

First, the spreading equilibrium is always a long-run equilibrium since

- $g_{1}(0.5)=g_{2}(0.5)=g(0.5)=1$.

Second, as a result of this, the derivative of $g$ evaluated at the spreading equilibrium, which is crucial for determining the stability properties of this equilibrium, is equal to the sum of the derivatives of the two auxiliary functions

\footnotetext{
${ }^{3}$ Differences in regional versus national pollution levels can influence Gorter's (2002) empirical puzzle that Europe is becoming less specialized at the regional level and more specialized at the country level.
} 
- $\quad g^{\prime}(0.5)=g_{2}(0.5) g_{1}{ }^{\prime}(0.5)+g_{1}(0.5) g_{2}{ }^{\prime}(0.5)=g_{1}{ }^{\prime}(0.5)+g_{2}{ }^{\prime}(0.5)$

Third, when evaluating the derivative of $g$ at the spreading equilibrium and the trade costs $\phi_{b r e a k, n p}$, the stability properties are dictated by the properties of the pollution function $g_{2}{ }^{\prime}$ only

- $\left.g_{1}\right|_{\phi_{\text {breaknp }}}(0.5)=\left.0 \Rightarrow g\right|_{\phi_{\text {breaknp }}}(0.5)=\left.g_{2}{ }^{\prime}\right|_{\phi_{\text {breaknp }}}(0.5)$

Fourth, recalling that at the spreading equilibrium $P_{1}(0.5)=P_{2}(0.5)=P_{\text {spread }}$ and noting that $P_{1}^{\prime}(0.5)=-P_{2}^{\prime}(0.5)$ the derivative of $g_{2}$ simplifies to

- $\quad g_{2}{ }^{\prime}(0.5)=\frac{-2 \theta}{1+P_{\text {spread }}} P_{1}^{\prime}(0.5) \Rightarrow \operatorname{sign}\left[g_{2}{ }^{\prime}(0.5)\right]=-\operatorname{sign}\left[P_{1}^{\prime}(0.5)\right]$

Since $g^{\prime}(0.5)<0$ is required for local stability of the spreading equilibrium, the above discussion implies that the stability properties of this equilibrium are strengthened if, and only if, a rise in the availaible human capital in country 1 raises the pollution level in country 1 . Despite the fact that a movement of human capital from country 2 to country 1 raises economic activity, income, and the production of manufactures in country 1 , the pollution level may nonetheless decline in country 1 as a result of the decline in food production. For equation (8') the relative impact of manufactures for pollution is measured by the parameter $\beta$. Thus, other things equal, an increase in $\beta$ increases the detrimental impact of the rising production of manufactures on pollution, which therefore raises the stability of the spreading equilibrium. This is illustrated in Figure 5 for a range of values of $\beta$. If $\beta=0$ only food production contributes to pollution, which therefore falls in country 1 as the stock of human capital increases. If $\beta=1$ only manufactures production contributes to pollution, which therefore rises in country 1 as the stock of human capital increases. For values of $\beta$ in between these two extreme cases, the pollution level may either continuously rise as the stock of human capital increases (for $\beta$ 'large'), or first rise and then fall (for $\beta$ 'small'). In the latter case, the detrimental impact of rising manufactures production on pollution is initially more important, while the beneficial impact of the fall in food production is eventually more important. 
Figure 5 Relative impact of manufactures on pollution $\beta$; example 1 and $T=1.3$

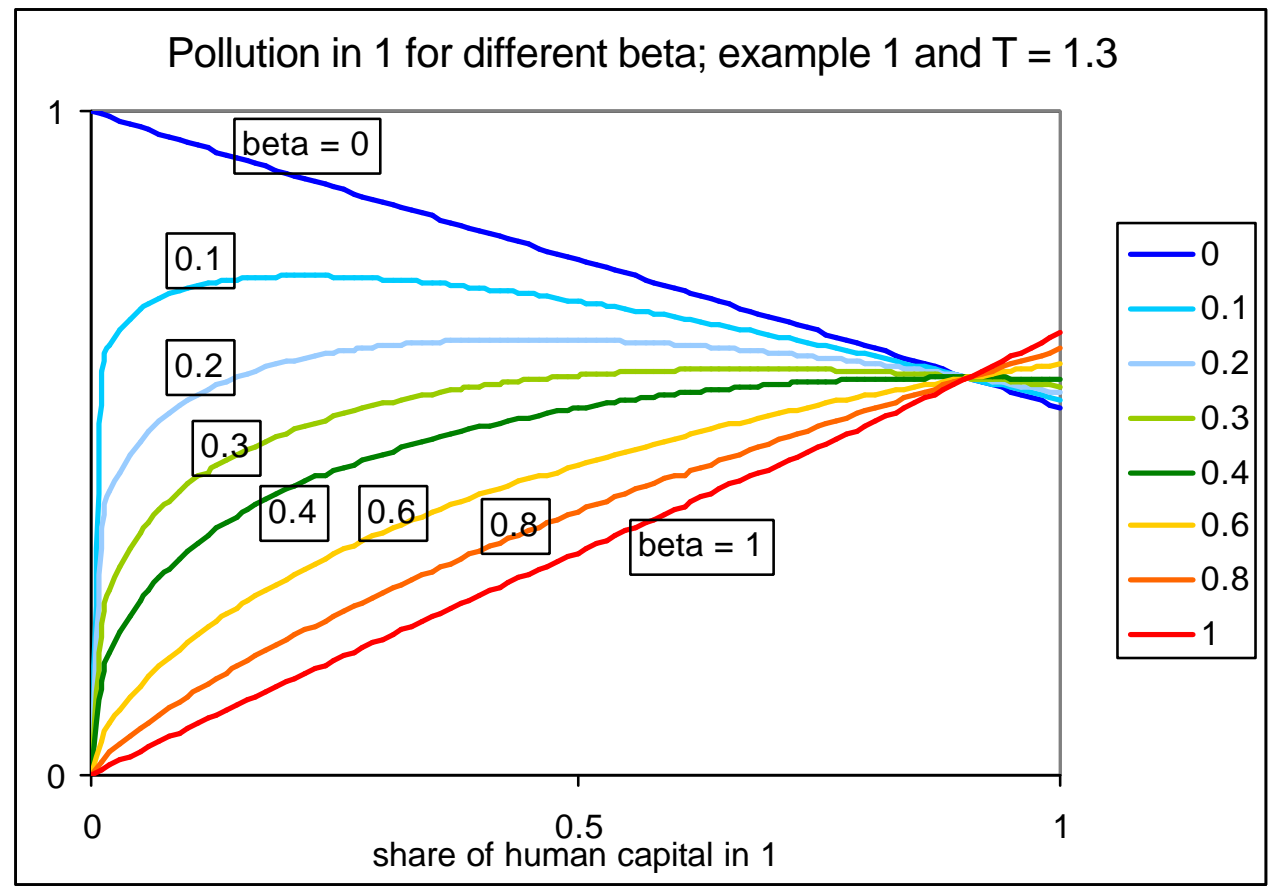

The levels of production of food and manufactures are, however, determined by the interaction between demand and supply factors in the economy. Together with the degree to which these production levels contribute to the extent of pollution as measured by the parameter $\beta$, this determines the total pollution level in country 1 . This is illustrated, as an example, in Figure 6 for a range of values of $\delta$, the share of income spent on manufactures. ${ }^{4}$ For low levels of $\delta$ (in the figure for $\delta=0.1 ; 0.2 ; 0.3$ ) the pollution level continuously rises as human capital is flowing into country 1 . For higher levels of $\delta$ (in the figure for $\delta=0.4 ; 0.5 ; 0.6$ ) the pollution level first increases and then decreases as human capital is flowing into country 1. Under those circumstances the rising production of manufactures is initially more important (raising pollution), while eventually the declining production of food is more important (leading to a fall in the pollution level). Proposition 3, derived in the appendix, gives the exact conditions under which the first effect is more important than the second effect.

\footnotetext{
${ }^{4}$ The figure only considers $\delta \leq 0.6$ as higher values would imply complete specialization in the coreperiphery equilibrium given the value of $\sigma$, see also proposition 2 .
} 
Figure 6 Pollution and share of income spent on manufactures $\delta$; example $1, T=1.3$

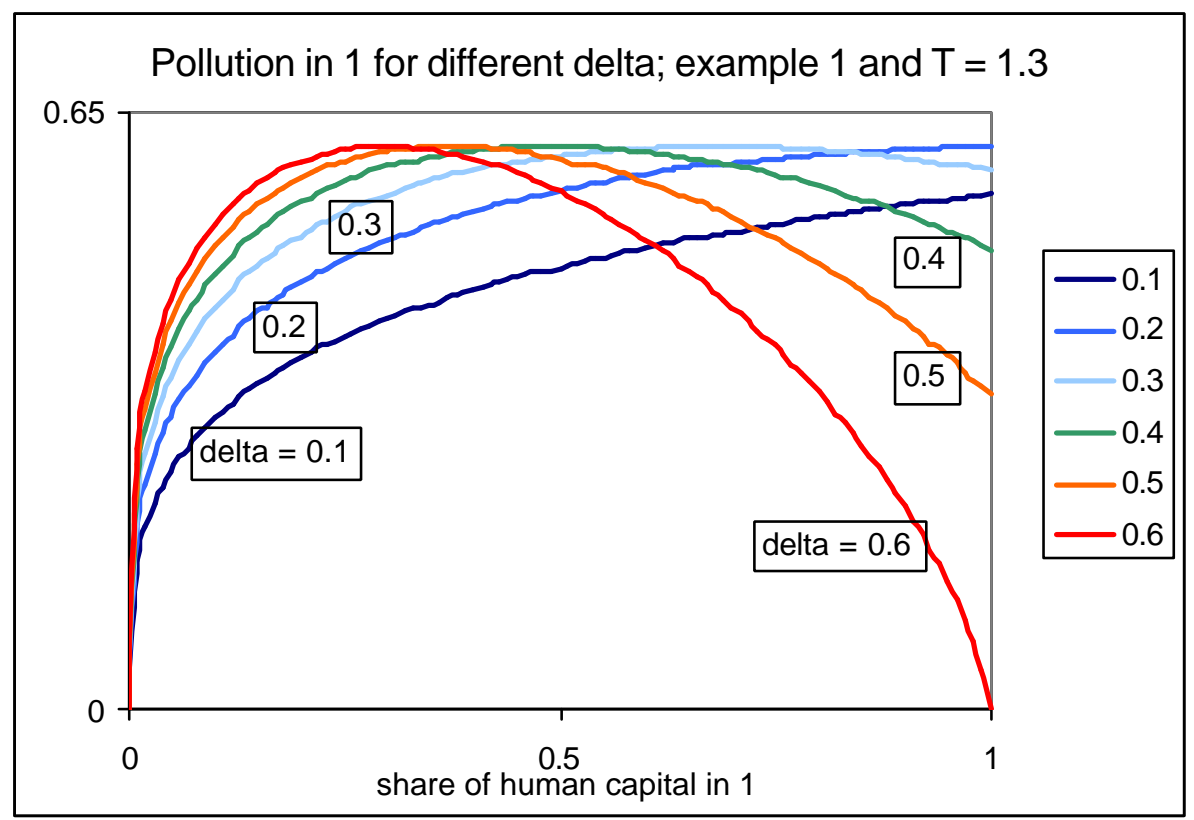

Proposition 3. The spreading equilibrium becomes more stable if, and only if, the inflow of human capital raises the pollution level. This is equivalent to the condition $\left(\varepsilon_{n x} / \varepsilon_{F}\right)>\gamma \delta /(1-\delta)$, where $\varepsilon_{n x}$ is the pollution elasticity of manufactures and $\varepsilon_{F}$ is the pollution elasticity of food. More specifically, at the trade costs $\phi_{\text {break,np }}$ the spreading equilibrium is stable if, and only if, this condition holds. For pollution equation ( $\left.8^{\prime}\right)$ the condition is equivalent to: $\beta /(1-\beta)>\gamma \delta /(1-\delta)$

In general, acknowledging the detrimental impact of pollution on welfare ensures that the spreading equilibrium is more stable provided the relative contribution of manufactures production to pollution is large enough relative to the share of income spent on manufactures. With pollution equation (8') a simple sufficient, but not necessary, condition is a relative contribution of manufactures production to pollution at least as large as the share of income spent on manufactures: $\beta \geq \delta$.

\section{Summary and conclusions}

The geographical economics literature focuses on the endogenous determination of the location of economic activity in a general equilibrium framework. The (in)stability of core-periphery economic structures and/or the extent to which spreading of economic activity is possible plays a crucial role in this analysis. Numerous factors 
affect the attractiveness of a location relative to other locations. The influence of many such factors has been analyzed, but the role of the environment has been neglected. This paper provides a simple first analysis of this aspect, by focusing on the interaction between location advantages and the negative pollution externalities associated with local production leading to lower welfare (disutility of air pollution, noise pollution, water pollution, visual externalities, etc.).

The model distinguishes between two goods (food and manufactures) and two factors of production (mobile human capital and immobile unskilled labor). Intuitively, if a relocation of inputs raises income and economic activity, resulting in a rising level of pollution which negatively affects welfare, one would expect that agglomeration of economic activity becomes less attractive, and thus less likely, and spreading of economic activity becomes more attractive, and thus more likely. As the analysis shows, this intuitive reasoning both is and is not justified. Economic agglomeration, that is a core-periphery structure, indeed becomes less stable, and therefore other things equal less likely, provided a rather mild sufficient condition holds. However, as human capital concentrates in one location the extent of economic activity as measured by the income level and the production of manufactures increases. Simultaneously, the production of food (which is unskilled labor intensive) falls, as unskilled labor becomes relatively more scarce. If the production of food contributes relatively sufficiently more to pollution from a welfare point of view than the production of manufactures, the incorporation of pollution effects may make the spreading equilibrium less stable, and therefore less likely to occur. The paper provides a simple necessary and sufficient condition for this outcome. 


\section{References}

Aghion, P., and P. Howitt (1998), Endogenous growth theory, MIT Press, Boston, U.S.A.

Andersson, F. and R. Forslid (2003), "Tax Competition and Economic Geography," Journal of Public Economic Theory 5(2): 279-304.

Baldwin, R. and P. Krugman (2004), "Agglomeration, Integration and Tax Harmonization," European Economic Review 48: 1-23.

Barbier, E.B. (1999), "Endogenous growth and natural resource scarcity," Environmental and Resource Economics 14: 51-74.

Brakman, S., H. Garretsen, R. Gigengack, C. van Marrewijk, and R. Wagenvoort (1996), "Negative feedbacks and industrial location," Journal of Regional Science 36: 631-652.

Brakman, S. H. Garretsen, C. van Marrewijk, and M. van den Berg (1999), “The return of Zipf: towards a further understanding of the rank-size distribution," Journal of Regional Science 39(1): 183-213.

Brakman, S., H. Garretsen, and C. Van Marrewijk (2001), An Introduction to Geographical Economics, Cambridge University Press, Cambridge, U.K.

Brakman, S., H Garretsen, and C. van Marrewijk (2002), "Locational competition and agglomeration: the role of government spending," CESifo Working Paper, No. 775 .

Conrad, K. (2003), "Locational competition under environmental regulation when input prices and productivity differ," paper presented at the workshop Spatial Environmental Economics, University of Heidelberg, May 2003.

CPB Netherlands Bureau for Economic Policy Analysis (2001), Capital Income Taxation in Europe, Trends and Trade-Offs, SDU Uitgevers, The Hague.

Dasgupta, P.S., and G.M. Heal (1979), Economic theory and exhaustible resources, Oxford University Press, Oxford, U.K.

Dixit, A., and J. Stiglitz (1977), "Monopolistic competition and optimal product diversity," American Economic Review 67: 297-308.

Dutch Ministry of Economic Affairs (1999), Nota Ruimtelijk Economisch Beleid (Report on Location Policy), The Hague.

Fisher, E.O’N., and C. van Marrewijk (1998), "Pollution and economic growth," The Journal of International Trade \& Economic Development 7: 55-69. 
Forslid, R. (1999), “Agglomeration with Human and Physical Capital: An Analytically Solvable Case," CEPR Discussion Paper, 2102, London.

Forslid, R. and G. Ottaviano (2003), “Trade and Location: Two Analytically solvable Cases," Journal of Economic Geography 3: 229-240.

Garg, P.C., and J.L. Sweeney (1978), “Optimal growth with depletable resources," Resources and Energy 1: 43-56.

Gorter, J. (2002), “The economic geography of Europe," CPB Report 2002/4.

Grimaud, A., and L. Rouge (2003), "Non-renewable resources and growth with vertical innovations: optimum, equilibrium and economic policies," Journal of Environmental Economics and Management 45(2): 433-453.

Kolstad, C.D., and J.A. Krautkraemer (1993), "Natural resource use and the environment," in: Handbook of Natural Resources and Energy Economics, Vol. III, A.V. Kneese and J.L. Sweeney (eds.), Elsevier Science Publishers: 1219-1265.

Krugman, P.R. (1991), "Increasing returns and economic geography," Journal of Political Economy 99: 483-499.

Marrewijk, C. van, F. van der Ploeg, and J. Verbeek (1993), "Is growth bad for the environment?: Pollution, abatement, and endogenous growth," The World Bank, Policy Research Working Paper, WPS 1151.

Neary, J.P. (2001), "Of Hype and Hyperbolas: Introducing the New Economic Geography," Journal of Economic Literature, vol. 39, pp. 536-561.

Ohlin, B. (1933), Interregional and international trade, Harvard University Press, Cambridge, MA.

Ottaviano, G. (2001), "Monopolistic Competition, Trade, and Endogenous Spatial Fluctuations," Regional Science and Urban Economics, Vol.31, pp.51-77.

Quaas, M. (2003), "On the new economic geography of agglomerations with environmental problems," mimeo, Interdisciplinary Institute for Environmental Economics, Heidelberg, Germany.

Rauscher, A. (2003), "Hot spots, high smoke stacks, and the geography of pollution," paper presented at the workshop Spatial Environmental Economics, University of Heidelberg, May 2003.

Samuelson, P.A. (1952), "Spatial price equilibrium and linear programming," American Economic Review, vol. 42, pp. 283-303. 
Schmutzler, A. (2003), "Spatial environmental economics: what are the issues?," paper presented at the workshop Spatial Environmental Economics, University of Heidelberg, May 2003.

Scholz, C.M., and G. Ziemes (1999), "Exhaustible resources, monopolistic competition and endogenous growth," Environmental and Resource Economics 13: 169-185.

Schou, P. (2000), "Polluting non-renewable resources and growth," Environmental and Resource Economics 16: 211-227.

Smulders, S., and R. Gradus (1996), "Pollution abatement and long term growth," European Journal of Political Economy 12: 505-532.

Smulders, S., A. van Soest, and C. Withagen (2004), "International trade, species diversity, and habitat conservation," Journal of Environmental Economics and Management 48(2): 891-910.

Stiglitz, J. (1994), "Growth with exhaustible natural resources: I) efficient and optimal growth, II) the competitive economy," Review of Economic Studies Symposium 41: 123-152.

Tahvonen, O. (1997), "Fossil fuels, stock externalities, and backstop technology," Canadian Journal of Economics 30: 855-874.

Tahvonen, O. (2001), "Economic growth and transitions between renewable and nonrenewable energy resources," European Economic Review 45: 1379-1398.

UNCTAD (1996), Incentives and Foreign Direct Investment, United Nations, New York.

Weibull, J.W. (1995), Evolutionary Game Theory, MIT Press, Cambridge, Mass.

Withagen, C. (1999), “Optimal extraction of non-renewable resources," in: Handbook of Environmental and Resource Economics, J.C.J.M. van den Bergh (ed.), Edward Elgar: 49-58. 


\section{Appendix}

Derivation of the short-run equilibrium

Substituting equations (4), (5), (9), and (11) in equation (10) gives

$$
\begin{aligned}
& \frac{\sigma}{\delta} w_{1}=\left[\frac{\left(L+w_{1} H_{1}\right)}{n_{1}+\phi n_{2}}+\frac{\phi\left(L+w_{2} H_{2}\right)}{n_{2}+\phi n_{1}}\right] \\
& \frac{\sigma}{\delta} w_{2}=\left[\frac{\left(L+w_{2} H_{2}\right)}{n_{2}+\phi n_{1}}+\frac{\phi\left(L+w_{1} H_{1}\right)}{n_{1}+\phi n_{2}}\right]
\end{aligned}
$$

These are two linear equations in $w_{1}$ and $w_{2}$ which can be solved easily. Note that we already substituted $L_{1}=L_{2}=L$ in these equations. The subsequent analysis normalizes the human capital stock to one $\left(H_{1}+H_{2}=1\right)$.

\section{Core-periphery equilibrium}

Suppose we have economic agglomeration in country 2 , such that $n_{1}=0$ and $n_{2}=1$. From equation (9) this implies that $Y_{1}=L$ and $Y_{2}=L+w_{2}$. Substituting that in the second equation of $(*)$ above gives $w_{2}=2 \delta L /(\sigma-\delta)$. This implies that the income level is $Y_{2}=(\sigma+\delta) L /(\sigma-\delta)$. Equations (5) and (7) then give the total production of manufactures and food: $n_{2} x_{2}=2 \delta \sigma L /(\sigma-\delta)$ and $F_{2}=[\sigma(1-2 \delta)+\delta] L /(\sigma-\delta)$. Obviously, country 1 produces only food: $F_{1}=L$. The pollution levels are derived using equation (8). For pollution function (8') we have:

$$
P_{1}=0 \quad \text { and } P_{2}=(\sigma(1-2 \delta)+\delta)^{1-\beta}(2 \delta \sigma)^{\beta}[L /(\sigma-\delta)] .
$$

The derivation is similar if there is economic agglomeration in country 1 .

\section{Spreading equilibrium}

Suppose we have spreading of economic activity, such that $n_{1}=n_{2}=1 / 2$. Substituting that in either $(*)$ equation above (and ignoring the subindex) gives $w=2 \delta L /(\sigma-\delta)$. Equation (9) gives the income level $Y=\sigma L /(\sigma-\delta)$. Similarly, using equations (5) and (7) gives manufactures $n x=\sigma \delta L /(\sigma-\delta)$ and food $F=\sigma(1-\delta) L /(\sigma-\delta)$. The level of pollution can be determined using (8). For pollution function (8') we get: $P=(1-\delta)^{1-\beta} \delta^{\beta} \sigma L /(\sigma-\delta)$. 


\section{Derivation of proposition 3}

The discussion in section 4 shows that the stability of the spreading equilibrium increases if, and only if, the pollution level rises as human capital is flowing into the country, when evaluated at $h=0.5$. Totally differentiating equation (8) gives

- $d P_{j}=P_{n x}{ }^{\prime} d n_{j} x_{j}+P_{F}{ }^{\prime} d F_{j}$

Define the pollution elasticities for manufactures $\varepsilon_{n x} \equiv(n x / P) P_{n x}{ }^{\prime}$ (note: with pollution equation ( $\left.8^{\prime}\right) \varepsilon_{n x}=\beta$ ) and for food $\varepsilon_{F} \equiv(F / P) P_{F}{ }^{\prime}$ (note: with pollution equation ( $\left.8^{\prime}\right) \varepsilon_{F}=1-\beta$ ), and substitute:

- $\frac{d P_{j}}{P_{j}}=\varepsilon_{n x} \frac{d\left(n_{j} x_{j}\right)}{n_{j} x_{j}}+\varepsilon_{F} \frac{d F_{j}}{F_{j}}$

Unskilled labor for the production of food cannot be used for the production of manufactures (production possibility frontier), see equation (7). Total differention gives $d F_{j}=-\gamma d\left(n_{j} x_{j}\right)$. Substituting this in the equation above gives

- $\frac{d P_{j}}{P_{j}}=\left[\varepsilon_{n x}-\gamma \frac{n_{j} x_{j}}{F_{j}} \varepsilon_{F}\right] \frac{d\left(n_{j} x_{j}\right)}{n_{j} x_{j}}$

This relationship holds quite generally, indicating that pollution will rise with an increase in the production of manufactures, depending on the relative mix of food production compared to manufactures production in relationship to the pollution elasticities for food and manufactures. In this case, however, we are interested in evaluating the term in square brackets at the spreading equilibrium. The production levels are derived above in this appendix and summarized in Table 2. Substition in the term in square brackets above implies that this term is positive iff

- $\frac{\varepsilon_{n x}}{\varepsilon_{F}}>\gamma \frac{n x_{\text {spread }}}{F_{\text {spread }}}=\gamma \frac{\delta}{1-\delta}$

For pollution equation (8') this holds if, and only if: $\frac{\beta}{1-\beta}>\gamma \frac{\delta}{1-\delta}$. 